\title{
COMO FAZER UMA ALÇA EM "Y DE ROUX" COM UMA CARGA DE GRAMPEADOR LINEAR CORTANTE
}

\section{HOW TO PERFORM A ROUX-IN-Y WITH ONE LINEAR LOOP WITH ONE LINEAR STAPLER LOAD}

\author{
José Júlio do Rêgo Monteiro Filho, TCBC-RJ'
}

O uso de suturas mecânicas na cirurgia gastrointestinal é um método consagrado quer seja pela economia de tempo operatório, quer seja pela diminuição da contaminação per operatória. Entretanto o custo que envolve o uso desses instrumentos muitas vezes limita o seu uso. Neste contexto, desenvolvemos uma maneira de confeccionar uma alça exclusa com somente um disparo de um grampeador linear longo ( 75 ou $80 \mathrm{~mm}$, dependendo do fabricante), seccionando a alça e realizando a anastomose jejuno-jejunal látero-lateral. Não encontramos descrição dessa técnica nos textos clássicos de cirurgia geral ${ }^{12345}$, e resolvemos divulgála dada a preocupação atual com custos.

Uma vez sendo necessária a confecção de uma alça em Y de Roux, para cirurgia gástrica, biliar ou pancreática, escolhemos o local adequado para a seção da alça, liberando a borda anti-mesentérica e reparando a alça com uma fita cardíaca (Figura 1). Em seguida medimos a distância para a anastomose jejuno jejunal (habitualmente $50 \mathrm{~cm}$ ) e posicionamos as alças para a anastomose láterolateral colocando um ponto de reparo unindo as alças e fazemos uma enterotomia em cada uma, onde iremos colocar as extremidades do grampeador. Um ramo do grampeador passa pela borda mesentérica junto ao reparo com fita cardíaca e entra pela enterotomia um pouco proximal na mesma alça; o outro ramo passa pela borda antimesentérica e entra pela enterotomia na outra alça. Pronto, é só ajustar as alças, fazer o disparo e suturar as enterotomias que o Y "está feito, faltando apenas a secção do mesentério. Geralmente cobrimos o local da secção do intestino com grampeador com um chuleio seromuscular de fio monofilamentar de polipropileno 3-0. Temos empregado esse método há oito anos, sem complicações relacionadas a o seu uso.

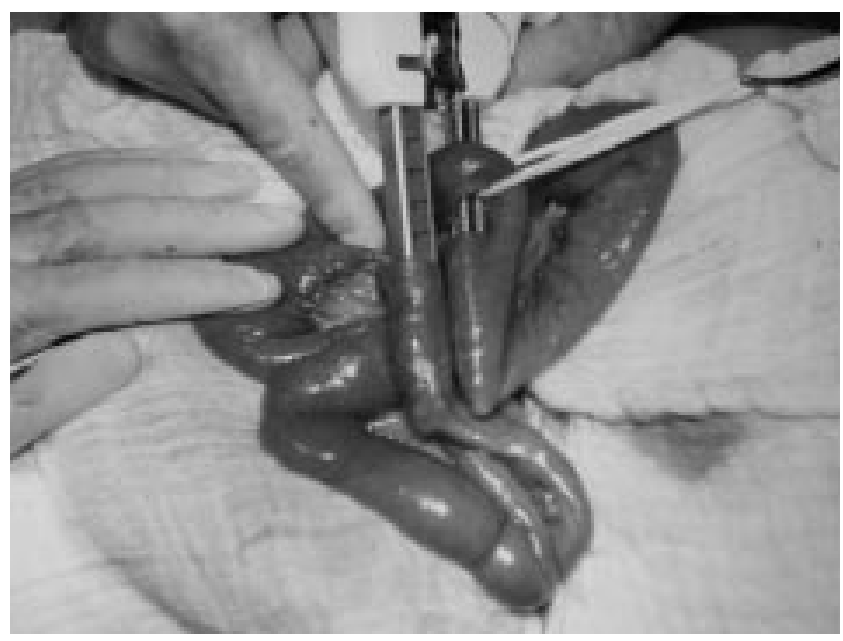

Figura 1 - Cirurgia exemplificando o disparo único.

1. Professor Titular de Clínica Cirúrgica da Faculdade de Medicina de Teresópolis; Cirurgião do Serviço de Cirurgia Geral do Hospital Miguel Couto Rio de Janeiro - RJ 


\section{ABSTRACT}

A technique of how to make a Roux in Y loop using only one stapler load is described. A long linear stapler must be placed in such a way that it cuts the intestinal limb and performs the jejuno-jejunal lateral anastomosis. Must be aditional stichers are placeo only the stapler holes (Rev. Col. Bras. Cir. 2006; 33(4): 256-257).

Key words: Suture techniques; Anastomosis, Roux-en-Y.

\section{REFERÊNCIAS}

1 - Hochberg J, Murray GF. Principles of operative surgery. In: Sabiston textbook of surgery. $15^{\text {th }}$ ed. North Caroline: Saunders; 1997. p. 253-62.

2 - Ravitch MM, Steichen FM. Technics of staple suturing in the gastrointestinal tract. Ann Surg. 1972;175(6):815-37.

3 - Sugerman HJ. Morbid obesity. In: Maingot R, Zinner MJ, Schwartz SI, editors. Maingot's abdominal operations. $10^{\text {th }}$ ed. Boston: Appleton \& Lange; 1997. p. 1057-78.

4 - Soybel ID, Zinner MJ. Stomach and duodenum: operative procedures. In: Maingot R, Zinner MJ, Schwartz SI, editors. Maingot's abdominal operations. $10^{\text {th }} \mathrm{ed}$. Boston: Massachusetts. Appleton \& Lange; 1997. p. 1079-127.
5 - Reber AH. Operations on the pancreas. In: Maingot R, Zinner MJ, Schwartz SI, editors. Maingot's abdominal operations. $10^{\text {th }}$ ed. Boston, Massachusetts: Appleton \& Lange; 1997. p. 2003-30.

Como citar este artigo:

Monteiro Filho JJR. Como fazer uma alça em "Y de Roux" com uma carga de grampeador linear cortante. Rev Col Bras Cir. [periódico na Internet] 2006 Jul-Ago;33(4). Disponível em URL: www.scielo.br/rcbc

Endereço para correspondência: José Júlio do Rego Monteiro Filho Rua Cosme Velho, 74 / 601 - Cosme Velho 22241-090 - Rio de janeiro - RJ

E-mail:josejulio@pobox.com 